.

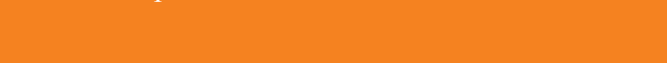

\title{
Stimulated Salivary Cortisol as a Noninvasive Diagnostic Tool for Adrenal Insufficiency
}

\author{
Yoon Ji Kim ${ }^{1,2}$, Jung Hee Kim ${ }^{1}$, A Ram Hong ${ }^{1}$, Kyeong Seon Park ${ }^{1}$, Sang Wan Kim ${ }^{1,3}$, Chan Soo Shin ${ }^{1}$, \\ Seong Yeon $\mathrm{Kim}^{1}$ \\ ${ }^{1}$ Department of Internal Medicine, Seoul National University Hospital, Seoul National University College of Medicine, Seoul; \\ ${ }^{2}$ Division of Endocrinology and Metabolism, Department of Internal Medicine, Mediplex Sejong Hospital, Incheon; \\ ${ }^{3}$ Department of Internal Medicine, Seoul Metropolitan Government Seoul National University Boramae Medical Center, Seoul, \\ Korea
}

Background: Salivary cortisol is routinely used as a diagnostic test for Cushing syndrome. The diagnostic use of salivary cortisol for adrenal insufficiency (AI), however, is less established. We aimed to investigate the utility of morning basal and adrenocorticotropic hormone-stimulated salivary cortisol in diagnosing $\mathrm{AI}$ in Korean adults.

Methods: We prospectively included 120 subjects (female, $n=70$ ) from Seoul National University Hospital. AI was defined as a stimulated serum cortisol level of $<496.8 \mathrm{nmol} / \mathrm{L}$ during the short Synacthen test (SST). Serum and saliva samples were drawn between 8:00 AM and 10:00 AM. Salivary cortisol levels were measured using an enzyme immunoassay kit.

Results: Thirty-four patients were diagnosed with AI according to the SST results. Age, sex, body mass index, serum albumin levels, and serum creatinine levels did not significantly differ between the normal and AI groups. Basal and stimulated salivary cortisol levels were positively correlated with basal $(r=0.538)$ and stimulated serum cortisol levels $(r=0.750)$, respectively (all $P<0.001)$. Receiver operating characteristic curve analysis yielded a cutoff level of morning basal salivary cortisol of $3.2 \mathrm{nmol} / \mathrm{L}$ (sensitivity, $84.9 \%$; specificity, $73.5 \%$; area under the curve $[\mathrm{AUC}]=0.822$ ). The optimal cutoff value of stimulated salivary cortisol was $13.2 \mathrm{nmol} / \mathrm{L}$ (sensitivity, 90.7\%; specificity, 94.1\%; AUC=0.959). Subjects with a stimulated salivary cortisol level above $13.2 \mathrm{nmol} / \mathrm{L}$ but a stimulated serum cortisol level below $496.8 \mathrm{nmol} / \mathrm{L}(n=2)$ had lower serum albumin levels than those showing a concordant response.

Conclusion: The diagnostic performance of stimulated salivary cortisol measurements after the SST was comparable to serum cortisol measurements for diagnosing AI.

Keywords: Saliva; Adrenal insufficiency; Hydrocortisone

\section{INTRODUCTION}

Primary or secondary adrenal insufficiency (AI) is diagnosed using serum total cortisol after dynamic tests such as the short Synacthen test (SST) or insulin tolerance test (ITT) [1,2]. How-

Received: 13 May 2020, Revised: 28 July 2020, Accepted: 20 August 2020 Corresponding author: Jung Hee Kim

Department of Internal Medicine, Seoul National University Hospital, Seoul National University College of Medicine, 101 Daehak-ro, Jongno-gu, Seoul 03080, Korea

Tel: +82-2-2072-4839, Fax: +82-2-764-2199, E-mail:jhkxingfu@gmail.com ever, since over $90 \%$ of serum total cortisol is bound to proteins such as corticosteroid-binding globulin (CBG) and albumin, biologically active free cortisol accounts for less than $10 \%$ of cortisol [3-5]. Therefore, the serum cortisol concentration depends on protein levels, which are often adversely affected by certain

Copyright $\odot 2020$ Korean Endocrine Society

This is an Open Access article distributed under the terms of the Creative Commons Attribution Non-Commercial License (https://creativecommons.org/ licenses/by-nc/4.0/) which permits unrestricted non-commercial use, distribution, and reproduction in any medium, provided the original work is properly cited. 
diseases, drugs, and clinical conditions [6,7]. Moreover, the pain and stress of blood sampling may affect serum cortisol concentrations. In contrast, salivary cortisol reflects bioactive free cortisol levels because serum albumin and CBG are too large to pass through the membrane of salivary cells $[8,9]$. Salivary cortisol is also closely correlated with serum free cortisol throughout the 24-hour period [7,10,11], indicating that salivary cortisol assays can be used to assess the circadian rhythm. In addition, salivary samples are obtained non-invasively and are easy to collect.

Salivary cortisol has been used to assess adrenal function since the 1980s $[12,13]$. Late-night salivary cortisol measurements are now widely used to diagnose Cushing syndrome [14]. By contrast, the use of salivary cortisol is less established for AI. Some researchers reported that morning basal salivary cortisol was useful in diagnosing AI $[15,16]$, whereas other researchers reported that it had low accuracy [17,18]. Several studies demonstrated that stimulated salivary cortisol levels after the SST or ITT distinguished patients with AI from healthy subjects [19-23]. However, salivary cortisol levels are generally 10- to 100 -fold lower than total serum levels, and the reliability of salivary cortisol is crucially dependent on the measurement method [20]. We aimed to investigate the diagnostic performance of morning basal and stimulated salivary cortisol levels in AI and to suggest optimal cut-off values for Korean adults.

\section{METHODS}

\section{Subjects}

We prospectively included 120 subjects who underwent the SST because they were suspected of having primary or secondary AI at Seoul National University Hospital from April 2013 to January 2014. The subjects had a history of pituitary disease $(n=67)$, adrenal disease $(n=10)$, or suspected secondary AI with iatrogenic Cushing syndrome $(n=43)$. Of these subjects, 31 patients underwent pituitary surgery and only one patient took a steroid replacement postoperatively. Seven patients had a history of adrenalectomy and three patients had taken prednisolone. Patients on corticosteroid replacement therapy were instructed to stop taking hydrocortisone or prednisolone at least 12 or 24 hours before testing, respectively. To prevent confounding factors, subjects with infection or bleeding in the oral cavity, a diagnosis of severe liver or renal disease, oral contraceptive use, and pregnancy were excluded (Fig. 1). This study was approved by the Institutional Review Board of the Seoul National University Hospital (IRB No. C-1303-068-474). Informed consent was obtained from all subjects.

\section{Salivary and serum cortisol measurements}

The subjects were instructed to avoid eating, drinking anything except water, brushing teeth, and smoking beginning 1 hour before the test. Basal serum and salivary cortisol samples were collected between 8:00 AM and 10:00 AM and the SST was performed subsequently. Stimulated serum and salivary cortisol levels were measured simultaneously at 30 and 60 minutes after intravenous administration of $250 \mu \mathrm{g}$ of synthetic adrenocorticotropic hormone $\left(\mathrm{ACTH}_{1-24}\right)$ (Synacthen, Novartis, Basel, Switzerland). Basal and stimulated serum blood samples were immediately centrifuged at $4^{\circ} \mathrm{C}$ for 15 minutes and the resulting serum was stored at $-20^{\circ} \mathrm{C}$ until use. Serum total cortisol was measured using a Packard Cobra Gamma Counter analyzer with commercial radioimmunoassay (RIA) kits (CIS Bio International, Saclay, France; inter-assay coefficient of variation [CV], $4.7 \%$; intra-assay CV, 4.2\%). Saliva was collected by chewing an oral cotton swab (Salivette, Sarstedt, Germany) for 2 to 5 min-

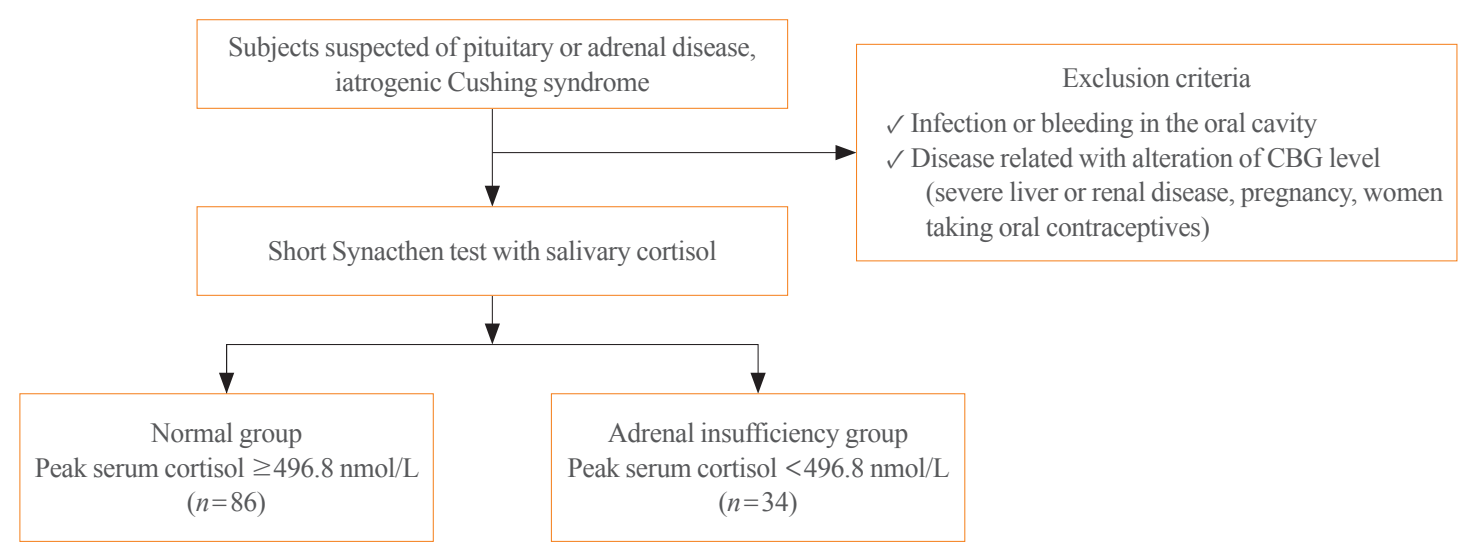

Fig. 1. Flow diagram of the study design. CBG, corticosteroid-binding globulin. 
utes and the samples were frozen at $-20^{\circ} \mathrm{C}$ until analysis. According to the manufacturer's protocol, freezing saliva samples were vortexed and centrifuged at 1,500 $\times g(3,000 \mathrm{rpm})$ for 15 minutes. Samples were kept at room temperature before adding them to the assay plate. Clear samples were pipetted into appropriate wells without disrupting the pellet. Salivary cortisol was analyzed using an enzyme immunoassay kit (EIA, Salimetrics Inc., State College, PA, USA) [24]. The intra-assay CV was $3.2 \%$ to $6.3 \%$, and the inter-assay CV was $5.7 \%$ to $6.8 \%$. The expected morning ranges of salivary cortisol derived using this kit were 3.1 to $22.4 \mathrm{nmol} / \mathrm{L}$ and 4.1 to $20.4 \mathrm{nmol} / \mathrm{L}$ in adult men and women aged 51 to 70 , respectively. The AI group was defined by a level of stimulated serum cortisol less than 496.8 nmol/L [1,2,25]. Serum creatinine and albumin were measured using a Hitachi 747 chemistry analyzer (Hitachi, Tokyo, Japan). The estimated glomerular filtration rate was calculated using the Modification of Diet in Renal Disease equation.

\section{Statistical analysis}

Data were presented as median and interquartile range or number (\%). The Mann-Whitney test was used for continuous variables. The correlation between serum and salivary cortisol levels was assessed using Spearman rank correlation analysis. The diagnostic performance of basal and stimulated salivary cortisol levels for predicting AI was evaluated using receiver operating characteristic (ROC) curve analysis. Linear regression analysis was used to develop a predictive equation for stimulated salivary cortisol. A $P$ value of less than 0.05 was considered to indicate statistical significance. All analyses were performed using
SPSS version 21.0 (IBM Corp., Armonk, NY, USA) and GraphPad Prism 5.0 (GraphPad Software Inc., La Jolla, CA, USA).

\section{RESULTS}

The clinical and biochemical parameters of study subjects, categorized by the serum cortisol response to the SST, are compared in Table 1. Eighty-six subjects showed a normal serum cortisol response to the SST (normal) and 34 subjects had an abnormal serum cortisol response to the SST (AI); three had primary AI and 31 had secondary AI. Age, sex, body mass index, serum albumin levels, and renal function did not significantly differ between the two groups. The AI group showed significantly lower basal and stimulated levels of serum and salivary cortisol than the normal group.

Fig. 2 presents the median cortisol levels of serum and saliva at each time point during the SST. In both groups, the median values of stimulated serum and salivary cortisol levels were highest at 60 minutes after stimulation. The median levels of serum and salivary cortisol at 60 minutes were significantly lower in the AI group than in the normal group $(351.9 \mathrm{nmol} / \mathrm{L}$ vs. $836.3 \mathrm{nmol} / \mathrm{L}$ for serum; $5.4 \mathrm{nmol} / \mathrm{L}$ vs. $23.4 \mathrm{nmol} / \mathrm{L}$ for saliva, respectively).

The positive relationship between stimulated serum and salivary cortisol levels was stronger than that between basal serum and salivary cortisol levels $(r=0.750$ and $r=0.538$, respectively; all $P<0.001$ ) (Fig. 3).

In the ROC curve analysis, the areas under the curve for basal and stimulated salivary cortisol were 0.822 and 0.959 , respectively (Fig. 4). The cutoff value of basal salivary cortisol for AI

Table 1. Clinical and Biochemical Parameters of Study Subjects Categorized by Their Serum Cortisol Response to the Short Synacthen Test

\begin{tabular}{lccc}
\hline Variable & Normal $(n=86)$ & AI $(n=34)$ & $P$ value \\
\hline Age, $\mathrm{yr}$ & $58(43-67)$ & $58(42-67)$ & 0.650 \\
Female sex & $53(61.6)$ & $17(50)$ & 0.244 \\
BMI, $\mathrm{kg} / \mathrm{m}^{2}$ & $23(21-26)$ & $24(22-27)$ & 0.188 \\
Serum albumin, g/dL & $4.3(4.0-4.5)$ & $4.2(3.9-4.4)$ & 0.257 \\
Serum creatinine, $\mathrm{mg} / \mathrm{dL}$ & $0.7(0.6-0.9)$ & $0.8(0.6-1.0)$ & 0.786 \\
Estimated GFR, $\mathrm{mL} / \mathrm{min} / \mathrm{l} .73 \mathrm{~m}^{2}$ & $117(95-134)$ & $113(84-145)$ & 0.941 \\
Basal serum cortisol, $\mathrm{nmol} / \mathrm{L}$ & $334(239-454)$ & $80(38-185)$ & $<0.001$ \\
Peak serum cortisol, $\mathrm{nmol} / \mathrm{L}$ & $836(674-940)$ & $352(204-453)$ & $<0.001$ \\
Basal salivary cortisol, $\mathrm{nmol} / \mathrm{L}$ & $6.18(3.8-9.0)$ & $2.42(1.23-3.75)$ & $<0.001$ \\
Peak salivary cortisol, $\mathrm{nmol} / \mathrm{L}$ & $23.6(16.8-34.4)$ & $5.73(3.56-8.83)$ & $<0.001$ \\
\hline
\end{tabular}

Values are expressed as median (interquartile range) or number (\%).

AI, adrenal insufficiency; BMI, body mass index; GFR, glomerular filtration rate. 

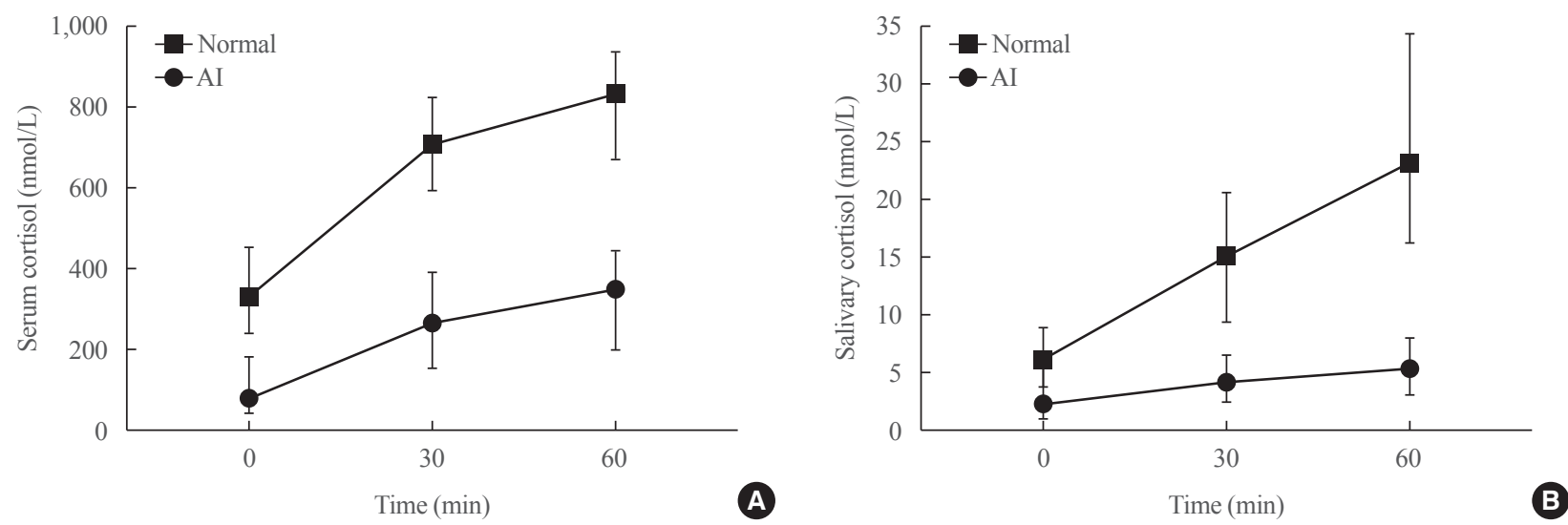

Fig. 2. Median cortisol values in (A) serum and (B) saliva at 30 and 60 minutes after intravenous administration of $250 \mu \mathrm{g}$ of synthetic adrenocorticotropic hormone $\left(\mathrm{ACTH}_{1-24}\right.$; Synacthen). The median levels of serum and salivary cortisol at 60 minutes were significantly lower in the adrenal insufficiency (AI) group than in the normal group $(351.9 \mathrm{nmol} / \mathrm{L}$ vs. $836.3 \mathrm{nmol} / \mathrm{L}$ for serum; $5.4 \mathrm{nmol} / \mathrm{L}$ vs. $23.4 \mathrm{nmol} / \mathrm{L}$ for saliva, respectively).
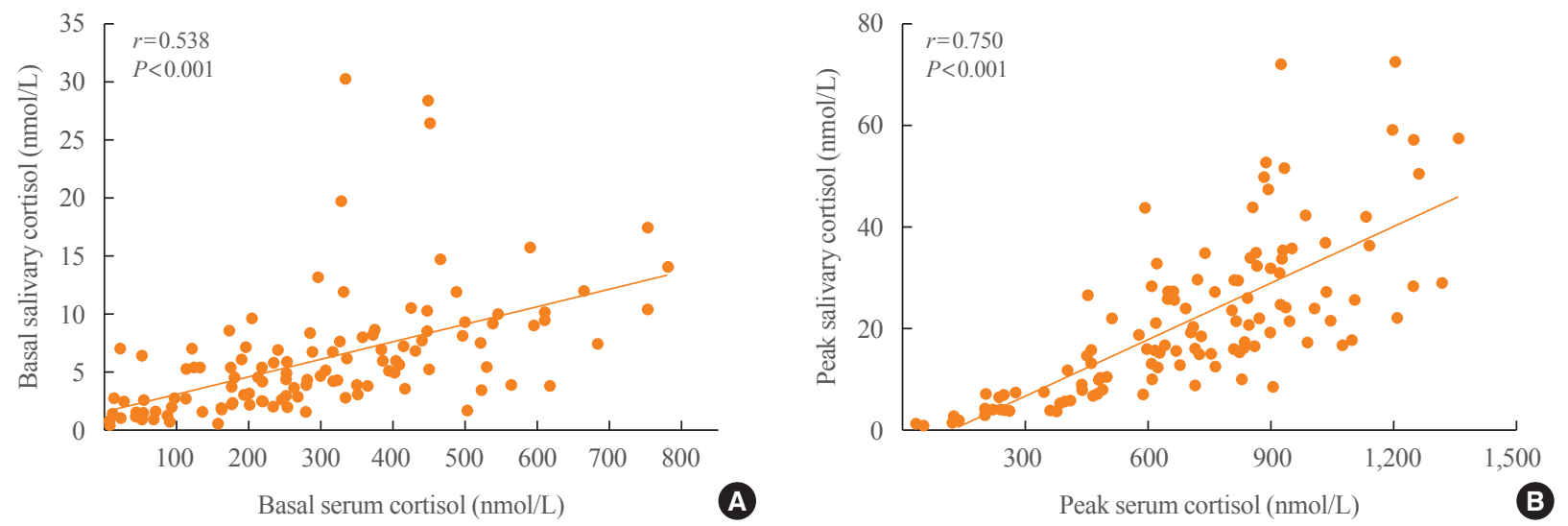

Fig. 3. Scatter plots between (A) basal or (B) stimulated serum and salivary cortisol levels. There were significant positive associations between serum and salivary cortisol levels at basal and peak time $(r=0.750$ and $r=0.538$, respectively; all $P<0.001)$.

was $3.2 \mathrm{nmol} / \mathrm{L}$ (sensitivity, $84.9 \%$; specificity, $73.5 \%$ ). The optimal cutoff value of stimulated salivary cortisol for AI during the SST was $13.2 \mathrm{nmol} / \mathrm{L}$ (sensitivity, 90.7\%; specificity, 94.1\%).

Subjects with a stimulated salivary cortisol level above 13.2 $\mathrm{nmol} / \mathrm{L}$ but a stimulated serum cortisol level below $496.8 \mathrm{nmol} / \mathrm{L}$ $(n=2)$ had lower serum albumin levels than those with a concordant response (Table 2). Of the remaining six hypoalbuminemic patients, two subjects showed a stimulated salivary cortisol level below $13.2 \mathrm{nmol} / \mathrm{L}$ and a serum cortisol level below $496.8 \mathrm{nmol} / \mathrm{L}$. The remaining four hypoalbuminemic patients showed consistent results: stimulated salivary cortisol levels above $13.2 \mathrm{nmol} / \mathrm{L}$ and serum cortisol levels above $496.8 \mathrm{nmol} / \mathrm{L}$. In addition, subjects with a stimulated salivary cortisol level below $13.2 \mathrm{nmol} / \mathrm{L}$ but a stimulated serum cortisol level above $496.8 \mathrm{nmol} / \mathrm{L}(n=8)$ had higher serum creatinine levels than
Table 2. Comparison of Clinical and Biochemical Characteristics between Subjects with Peak Salivary Cortisol Levels above and below $13.2 \mathrm{nmol} / \mathrm{L}$ among Subjects with Adrenal Insufficiency

\begin{tabular}{lccc}
\hline \multirow{2}{*}{ Variable } & \multicolumn{2}{c}{ Peak salivary cortisol, $\mu \mathrm{g} / \mathrm{dL}$} & \\
\cline { 2 - 3 } & $\begin{array}{c}\geq 13.2 \\
(n=2)\end{array}$ & $\begin{array}{c}<13.2 \\
(n=32)\end{array}$ & \\
\hline Age, $\mathrm{yr}$ & $64(57-71)$ & $57(42-67)$ & 0.357 \\
BMI, $\mathrm{kg} / \mathrm{m}^{2}$ & $22(20-24)$ & $25(22-27)$ & 0.392 \\
Serum albumin, $\mathrm{mg} / \mathrm{dL}$ & $3.2(3.1-3.2)$ & $4.2(4.0-4.5)$ & 0.032 \\
Serum creatinine, $\mathrm{mg} / \mathrm{dL}$ & $1.0(0.9-1.1)$ & $0.8(0.6-1.0)$ & 0.200 \\
\hline $\begin{array}{l}\text { Values are expressed as median (range). } \\
\text { BMI, body mass index. }\end{array}$ & & \\
\hline
\end{tabular}



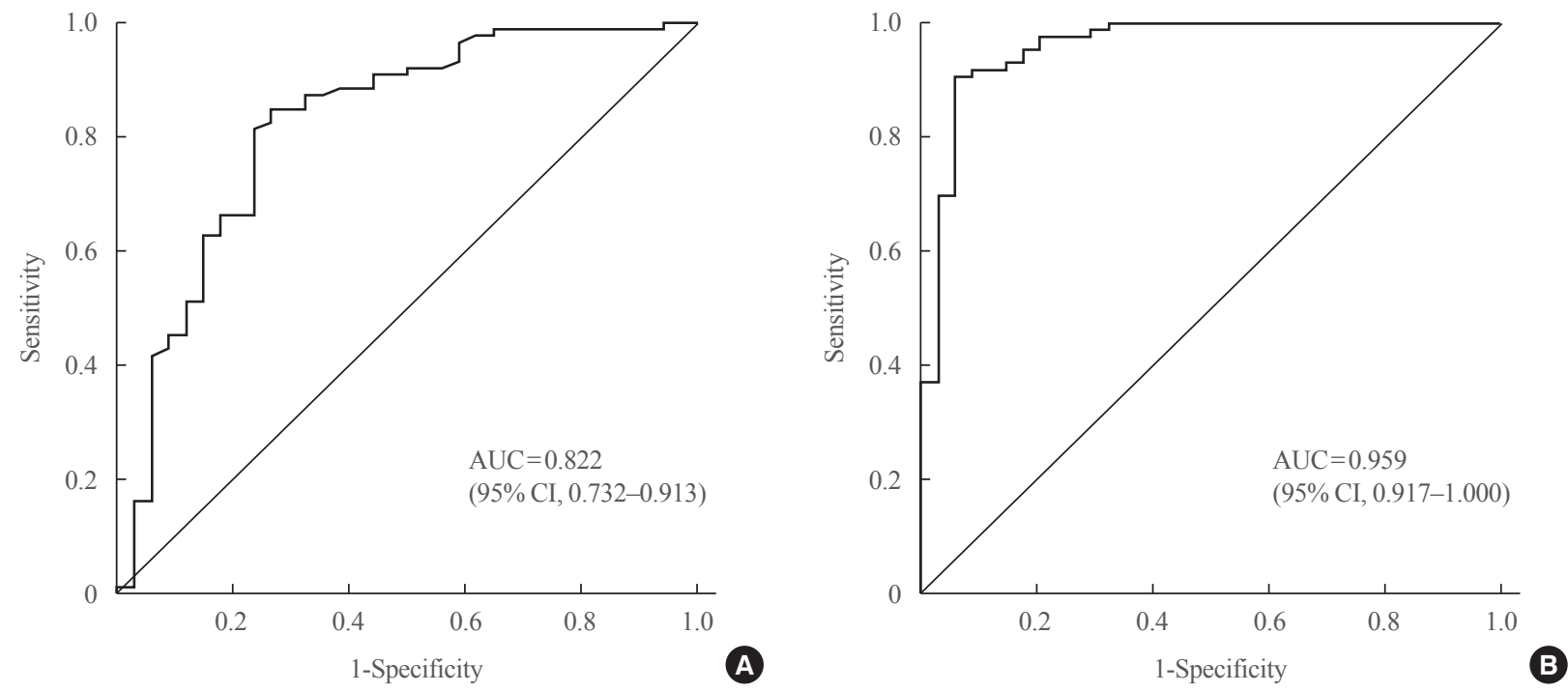

Fig. 4. Receiver operating characteristic (ROC) curve of (A) basal and (B) stimulated salivary cortisol in the diagnosis of adrenal insufficiency (AI) in all subjects $(n=120)$. The areas under the curve (AUCs) for basal and stimulated salivary cortisol were 0.822 and 0.959 , respectively. The cutoff value of basal salivary cortisol for AI was $3.2 \mathrm{nmol} / \mathrm{L}$ (sensitivity, $84.9 \%$; specificity, $73.5 \%$ ). The optimal cutoff value of stimulated salivary cortisol for AI during the SST was $13.2 \mathrm{nmol} / \mathrm{L}$ (sensitivity, 90.7\%; specificity, $94.1 \%$ ). CI, confidence interval.

those with a concordant response. The estimated glomerular filtration rate of men was significantly lower in those with a discordant response; however, this finding was not noted in women (data not shown).

\section{DISCUSSION}

In the present study, basal and stimulated salivary cortisol levels were found to be closely correlated with serum total cortisol levels. The measurements of stimulated salivary cortisol levels using the SST were comparable to the measurements of stimulated serum cortisol in terms of diagnostic performance for AI. We suggest an optimal cutoff value of $13.2 \mathrm{nmol} / \mathrm{L}$ for stimulated salivary cortisol to diagnose AI.

The diagnostic value of morning basal salivary cortisol levels has been investigated for AI, given that cortisol release peaks in the morning in healthy persons. The literature does not affirm the diagnostic usefulness of morning basal salivary cortisol levels. Cutoff values for morning salivary cortisol have been reported to be 5.9 to $42.2 \mathrm{nmol} / \mathrm{L}$, with a specificity of $35 \%$ to $93.3 \%$ $[15,16,18]$. The mean values of basal salivary cortisol in several studies were similar to $[7,8,15,17,19]$ or higher than $[22,25,26]$ those in our data. The sampling time may explain the discrepancy. In our study, saliva was collected at around 9:00 AM, but in other studies, saliva was sampled at 6:00 to 8:00 AM, when serum cortisol levels are highest during the 24-hour period. More- over, the measurement methods were different among studies, ranging from EIA to lipid chromatography-tandem mass spectrometry (LC-MS/MS). Morning salivary cortisol levels in normal subjects have been shown to overlap with those in AI patients [18]. We also found an intermediate diagnostic power of morning salivary cortisol at a cutoff value of $3.2 \mathrm{nmol} / \mathrm{L}$ with a specificity of $73.5 \%$. Thus, a cutoff value of $3.2 \mathrm{nmol} / \mathrm{L}$ for morning salivary cortisol levels can be used as a noninvasive screening tool for AI, as a way to determine whether or not the stimulation test should be performed.

Stimulated salivary cortisol has drawn interest due to the well-established method of diagnosing AI using serum cortisol. Among stimulation tests, the SST has been commonly used owing to its safety and accuracy, although the ITT is still considered to be the gold standard. Intriguingly, the cutoff value using the SST $(13.2 \mathrm{nmol} / \mathrm{L})$ suggested by our data is similar to the cutoff value reported by Karpman et al. [20] using the ITT (13.3 $\mathrm{nmol} / \mathrm{L}$ ). Several studies have advocated for the usefulness of stimulated salivary cortisol levels $[19,22,26,27]$. Cornes et al. [23] suggested that the cutoff values of $15 \mathrm{nmol} / \mathrm{L}$ for salivary cortisol levels were extrapolated from the established cutoff values of $550 \mathrm{nmol} / \mathrm{L}$ for serum cortisol levels (Roche assay) after the SST. Given the recommended cutoff value of $500 \mathrm{nmol} / \mathrm{L}$ for serum cortisol in our study, the salivary cortisol cutoff value of $13.2 \mathrm{nmol} / \mathrm{L}$ may be appropriate for diagnosing AI. Nolan et al. [28] suggested much higher cutoff values for salivary corti- 
sol ( $26 \mathrm{nmol} / \mathrm{L}$ at 60 minutes after the SST), but low specificity is a limitation of that level.

The reliability of salivary cortisol measurements in diagnosing AI depends on the methodology and study protocol. The optimal dose of Synacthen is controversial. A low-dose $(1 \mu \mathrm{g}) \mathrm{ACTH}_{1-24}$ stimulation test has been advocated in several studies instead of the standard dose $(250 \mu \mathrm{g})$ of $\mathrm{ACTH}_{1-24}$ to assess adrenal sensitivity, rather than maximum capacity $[26,27,29]$. However, the diagnostic superiority of low-dose SST remains unclear [30]. Contreras et al. [21] reported that the normal response of salivary cortisol after the low-dose SST was $20 \mathrm{nmol} / \mathrm{L}$ at 30 minutes, which is higher than we found using the standard dose of Synacthen. In addition, $\mathrm{C}_{\max }$ (peak serum level achieved) and $\mathrm{T}_{\max }$ (the time at which the peak serum level was achieved) showed significantly higher values in patients who received the high-dose SST than in those who received the low-dose SST [31]. Thus, different cutoff values for salivary cortisol at different time intervals should be used. Based on our study, we suggest a cutoff value of $13.2 \mathrm{nmol} / \mathrm{L}$ at 60 minutes after stimulation with a standard dose $(250 \mu \mathrm{g})$ of $\mathrm{ACTH}_{1-24}$.

Although salivary cortisol can be altered by $11 \beta$-hydroxysteroid dehydrogenase, the difference in variability between serum and salivary cortisol levels was quite small. Basal and stimulated salivary cortisol levels showed significant correlations with basal and stimulated serum cortisol levels ( $r=0.5$ to 0.8$)$, respectively, as seen in other studies $[8,15,32,33]$, Hence, Karpman et al. [20] reported the following equation relating salivary cortisol levels to serum cortisol levels: salivary cortisol $=0.048 \times$ serum cortisol- 0.264 . When this equation was applied to our data, the calculated salivary cortisol levels were closely correlated with our formula $(r=0.982, P<0.001)$.

The measurement of serum total cortisol levels is altered by CBG or albumin levels. Therefore, AI could be overestimated in septic or critically ill patients with hypoproteinemia $[7,32,34]$. Salivary cortisol is a much better index of serum free cortisol than serum total cortisol, which is also supported by our data. Although the number of patients with hypoalbuminemia in the AI group was insufficient $(n=2)$, they showed higher stimulated salivary cortisol levels than serum cortisol levels during the SST. Likewise, AI patients with high CBG levels, such as hyperestrogenic subjects, may show spuriously normal serum total cortisol levels [27]. In addition, subjects with lower renal function had low salivary but high serum cortisol levels. CBG levels are known to increase in patients with chronic kidney disease due to decreased CBG clearance $[33,35]$.

The strengths of the present study include its prospective na- ture and large sample size compared with previous studies. We used consistent cortisol assay methodology and average values of salivary cortisol obtained by duplication. We assessed the clinical applicability of salivary cortisol levels in Korean AI patients. The limitations of the study include a lack of recruitment of healthy control subjects and the use of the high-dose SST instead of the ITT, the gold standard. However, although some discrepancies exist [2], an excellent correlation between the SST and the ITT has been reported [22]. Regarding salivary cortisol measurements, ITT is harder to perform because insulin-induced hypoglycemia should be treated with food and may be accompanied by cardiovascular and neurological complications. Another limitation is that the measurements of salivary cortisol by EIA could differ from those obtained using other techniques such as RIA or LC-MS/MS. One study supported a correlation between RIA and EIA [8]. In another study, salivary cortisone had a stronger correlation than salivary cortisol with serum cortisol [31]. Nevertheless, we could not measure levels of salivary cortisone, which may be converted by $11 \beta$-hydroxysteroid dehydrogenase type 2. Moreover, we did not exclude subjects who had taken herbal medications. Licorice, which is included in many herbal medications, inhibits $11 \beta$-hydroxysteroid dehydrogenase type 2 and thereby falsely elevates salivary cortisol levels.

In conclusion, morning basal salivary cortisol may be useful as a noninvasive screening tool. The diagnostic power of stimulated salivary cortisol levels measured using the SST was comparable with that of stimulated serum cortisol levels measured using the SST in diagnosing AI. The measurement of salivary cortisol levels may be useful for diagnosing AI in patients with altered CBG levels and intravenous catheterization failure. Further studies in Koreans are needed to validate our proposed cutoff value of $13.2 \mathrm{nmol} / \mathrm{L}$.

\section{CONFLICTS OF INTEREST}

No potential conflict of interest relevant to this article was reported.

\section{ACKNOWLEDGMENTS}

This research received a grant from Seoul National University Hospital (grant number 03-2013-0310).

This work was presented in abstract form at the 2014 Seoul International Congress of Endocrinology and Metabolism in Korea. 


\section{AUTHOR CONTRIBUTIONS}

Conception or design: J.H.K., S.Y.K. Acquisition, analysis, or interpretation of data: Y.J.K., J.H.K., A.R.H., K.S.P. Drafting the work or revising: Y.J.K., J.H.K., S.W.K., C.S.S., S.Y.K. Final approval of the manuscript: J.H.K., S.W.K., C.S.S., S.Y.K.

\section{ORCID}

Yoon Ji Kim https://orcid.org/0000-0001-9730-4120

Jung Hee Kim https://orcid.org/0000-0003-1932-0234

\section{REFERENCES}

1. Stewart PM, Corrie J, Seckl JR, Edwards CR, Padfield PL. A rational approach for assessing the hypothalamo-pituitaryadrenal axis. Lancet 1988;1:1208-10.

2. Dorin RI, Qualls CR, Crapo LM. Diagnosis of adrenal insufficiency. Ann Intern Med 2003;139:194-204.

3. Brien TG. Human corticosteroid binding globulin. Clin Endocrinol (Oxf) 1981;14:193-212.

4. Coolens JL, Van Baelen H, Heyns W. Clinical use of unbound plasma cortisol as calculated from total cortisol and corticosteroid-binding globulin. J Steroid Biochem 1987;26: 197-202.

5. Perogamvros I, Ray DW, Trainer PJ. Regulation of cortisol bioavailability: effects on hormone measurement and action. Nat Rev Endocrinol 2012;8:717-27.

6. Hammond GL. Determinants of steroid hormone bioavailability. Biochem Soc Trans 1997;25:577-82.

7. Arafah BM, Nishiyama FJ, Tlaygeh H, Hejal R. Measurement of salivary cortisol concentration in the assessment of adrenal function in critically ill subjects: a surrogate marker of the circulating free cortisol. J Clin Endocrinol Metab 2007; 92:2965-71.

8. Wood P. Salivary steroid assays: research or routine? Ann Clin Biochem 2009;46(Pt 3):183-96.

9. Groschl M. Current status of salivary hormone analysis. Clin Chem 2008;54:1759-69.

10. Dorn LD, Lucke JF, Loucks TL, Berga SL. Salivary cortisol reflects serum cortisol: analysis of circadian profiles. Ann Clin Biochem 2007;44(Pt 3):281-4.

11. Galbois A, Rudler M, Massard J, Fulla Y, Bennani A, Bonnefont-Rousselot $\mathrm{D}$, et al. Assessment of adrenal function in cirrhotic patients: salivary cortisol should be preferred. J Hepatol 2010;52:839-45.
12. Inder WJ, Dimeski G, Russell A. Measurement of salivary cortisol in 2012: laboratory techniques and clinical indications. Clin Endocrinol (Oxf) 2012;77:645-51.

13. Riad-Fahmy D, Read GF, Walker RF. Salivary steroid assays for screening endocrine function. Postgrad Med J 1980; 56 Suppl 1:75-8.

14. Nieman LK, Biller BM, Findling JW, Newell-Price J, Savage MO, Stewart PM, et al. The diagnosis of Cushing's syndrome: an Endocrine Society Clinical Practice Guideline. J Clin Endocrinol Metab 2008;93:1526-40.

15. Ceccato F, Barbot M, Zilio M, Ferasin S, Occhi G, Daniele A, et al. Performance of salivary cortisol in the diagnosis of Cushing's syndrome, adrenal incidentaloma, and adrenal insufficiency. Eur J Endocrinol 2013;169:31-6.

16. Langelaan MLP, Kisters JMH, Oosterwerff MM, Boer AK. Salivary cortisol in the diagnosis of adrenal insufficiency: cost efficient and patient friendly. Endocr Connect 2018;7: 560-6.

17. Deutschbein T, Broecker-Preuss M, Flitsch J, Jaeger A, Althoff R, Walz MK, et al. Salivary cortisol as a diagnostic tool for Cushing's syndrome and adrenal insufficiency: improved screening by an automatic immunoassay. Eur J Endocrinol 2012;166:613-8.

18. Restituto P, Galofre JC, Gil MJ, Mugueta C, Santos S, Monreal JI, et al. Advantage of salivary cortisol measurements in the diagnosis of glucocorticoid related disorders. Clin Biochem 2008;41:688-92.

19. Deutschbein T, Unger N, Mann K, Petersenn S. Diagnosis of secondary adrenal insufficiency in patients with hypothalamic-pituitary disease: comparison between serum and salivary cortisol during the high-dose short synacthen test. Eur J Endocrinol 2009;160:9-16.

20. Karpman MS, Neculau M, Dias VC, Kline GA. Defining adrenal status with salivary cortisol by gold-standard insulin hypoglycemia. Clin Biochem 2013;46:1442-6.

21. Contreras LN, Arregger AL, Persi GG, Gonzalez NS, Cardoso EM. A new less-invasive and more informative lowdose ACTH test: salivary steroids in response to intramuscular corticotrophin. Clin Endocrinol (Oxf) 2004;61:675-82.

22. Laudat MH, Cerdas S, Fournier C, Guiban D, Guilhaume B, Luton JP. Salivary cortisol measurement: a practical approach to assess pituitary-adrenal function. J Clin Endocrinol Metab 1988;66:343-8.

23. Cornes MP, Ashby HL, Khalid Y, Buch HN, Ford C, Gama R. Salivary cortisol and cortisone responses to tetracosactrin (synacthen). Ann Clin Biochem 2015;52(Pt 5):606-10. 
24. Raff H, Homar PJ, Skoner DP. New enzyme immunoassay for salivary cortisol. Clin Chem 2003;49:203-4.

25. Kosak M, Hana V, Hill M, Simunkova K, Lacinova Z, Krsek M, et al. Serum cortisol seems to be a more appropriate marker for adrenocortical reserve evaluation in ACTH test in comparison to salivary cortisol. Physiol Res 2014;63: 229-36.

26. Simunkova K, Hampl R, Hill M, Doucha J, Starka L, Vondra K. Salivary cortisol in low dose (1 microg) ACTH test in healthy women: comparison with serum cortisol. Physiol Res 2007;56:449-53.

27. Marcus-Perlman Y, Tordjman K, Greenman Y, Limor R, Shenkerman G, Osher E, et al. Low-dose ACTH (1 microg) salivary test: a potential alternative to the classical blood test. Clin Endocrinol (Oxf) 2006;64:215-8.

28. Nolan BJ, Sorbello J, Brown N, Dimeski G, Inder WJ. Characterization of the serum and salivary cortisol response to the intravenous $250 \mu \mathrm{g}$ ACTH 1-24 stimulation test. Endocrine 2018;59:520-8.

29. Dickstein G, Shechner C, Nicholson WE, Rosner I, ShenOrr Z, Adawi F, et al. Adrenocorticotropin stimulation test: effects of basal cortisol level, time of day, and suggested new sensitive low dose test. J Clin Endocrinol Metab 1991;
72:773-8.

30. Cho HY, Kim JH, Kim SW, Shin CS, Park KS, Kim SW, et al. Different cut-off values of the insulin tolerance test, the high-dose short Synacthen test $(250 \mu \mathrm{g})$ and the low-dose short Synacthen test $(1 \mu \mathrm{g})$ in assessing central adrenal insufficiency. Clin Endocrinol (Oxf) 2014;81:77-84.

31. Elder CJ, Harrison RF, Cross AS, Vilela R, Keevil BG, Wright NP, et al. Use of salivary cortisol and cortisone in the high- and low-dose synacthen test. Clin Endocrinol (Oxf) 2018;88:772-8.

32. Arafah BM. Hypothalamic pituitary adrenal function during critical illness: limitations of current assessment methods. J Clin Endocrinol Metab 2006;91:3725-45.

33. Meuwese CL, Carrero JJ. Chronic kidney disease and hypothalamic-pituitary axis dysfunction: the chicken or the egg? Arch Med Res 2013;44:591-600.

34. Hamrahian AH, Oseni TS, Arafah BM. Measurements of serum free cortisol in critically ill patients. N Engl J Med 2004;350:1629-38.

35. Arregger AL, Cardoso EM, Zucchini A, Aguirre EC, Elbert A, Contreras LN. Adrenocortical function in hypotensive patients with end stage renal disease. Steroids 2014;84:5763. 